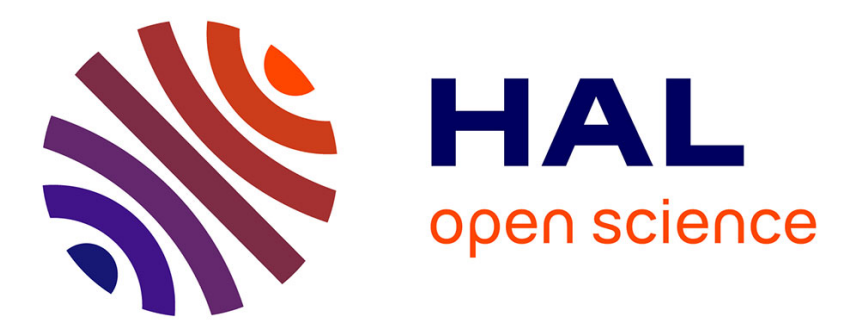

\title{
Potential of Building Information Modeling - BIM - Tools Inside Brazilian Civil Construction Scenery
}

Samuel Dos Santos, Oduvaldo Vendrametto, Miguel León González, Creusa Fernandes Correia

\section{- To cite this version:}

Samuel Dos Santos, Oduvaldo Vendrametto, Miguel León González, Creusa Fernandes Correia. Potential of Building Information Modeling - BIM - Tools Inside Brazilian Civil Construction Scenery. IFIP International Conference on Advances in Production Management Systems (APMS), Sep 2015, Tokyo, Japan. pp.299-307, 10.1007/978-3-319-22756-6_37 . hal-01417496

\author{
HAL Id: hal-01417496 \\ https://hal.science/hal-01417496
}

Submitted on 15 Dec 2016

HAL is a multi-disciplinary open access archive for the deposit and dissemination of scientific research documents, whether they are published or not. The documents may come from teaching and research institutions in France or abroad, or from public or private research centers.
L'archive ouverte pluridisciplinaire HAL, est destinée au dépôt et à la diffusion de documents scientifiques de niveau recherche, publiés ou non, émanant des établissements d'enseignement et de recherche français ou étrangers, des laboratoires publics ou privés.

\section{(c)(1)}

Distributed under a Creative Commons Attribution| 4.0 International License 


\title{
Potential of Building Information Modeling - BIM - Tools inside Brazilian Civil Construction Scenery
}

\author{
Samuel Dereste dos Santos (samuel_dereste@yahoo.com.br) 1,2, Oduvaldo \\ Vendrametto (oduvaldov@uol.com.br) ${ }^{1}$, Miguel León González \\ (miguel.leon@uol.com.br) ${ }^{2}$, Creusa Fernandes Correia ${ }^{2}$ \\ (creusa.profmategmail.com)
}

1 Paulista University-UNIP, Dr. Bacelar St. 1212, São Paulo, Brazil 2 Cruzeiro do Sul University-UNICSUL, Dr. Ussiel Cirillo Ave. 225, São Paulo, Brazil

\begin{abstract}
The software utilization in civil construction Brazilian industry has been suffering since the 90 's a continuous implementation considering small, medium and large companies. In this scenery, emerged CAD - Computer Aided Design -and BIM - Building Information Modeling - tools, that have different concepts and operation. The objective is analyze BIM tools potential in Brazilian scenery, stablishing a comparison between the performance of CAD and BIM tools. In order to understand the variables of the subject, was done a technical review focused on most cited authors of the area, as well as a survey, applied to experts of project development in Brazil. The results have shown that BIM tools are more effective than $\mathrm{CAD}$ tools considering both basic projects until final projects, and for future challenges, BIM solutions can optimize project process in Brazil's civil construction enterprises.
\end{abstract}

Keywords: CAD, BIM, Software productivity, Basic Projects, Final Projects

\section{Introduction}

The civil construction industry in Brazil has been suffering, since 2006, a great amount of investments that resulted in a great development in this area, since housing construction until infrastructure works. Besides, problems with project development and construction process are very common in this area. When compared with other industries of the country, it is still considered delayed because of work organization, work division, labor, etc. [1].

Analyzing the project tools used in this area worldwide, the CAD - Computer Aided Design - software are very common. This family of tool was responsible for the replacement, from clipboard to computer, of the project process in the engineering area. Used in the aeronautics, mechanics and construction, it has made the project process more effective, allowing the utilization of digital files that could be transmitted and edited in a faster way, changing the scenario of project development.

adfa, p. 1, 2011 .

(C) Springer-Verlag Berlin Heidelberg 2011 
In the civil construction area, the CAD tools have presented bottlenecks of integration that difficult the evolution in a vector platform. To allow the integration with another software, it is necessary the joint of information that are not possible in this platform. Considered a CAD evolution, emerges the BIM - Building Information Modeling - tools.

The main difference between CAD and BIM tools is the object construction. While $\mathrm{CAD}$ are vector information, the BIM models are parametric, which allows the insertion of a different kind of information, like material type, cost, time do produce, codes, etc. Other important characteristic is the possibility of project development in different integrated platforms, what allows different professionals (Architects, Engineers, and Designers) working in a same model real-time, what wasn't possible in CAD platforms.

The BIM technology has been used worldwide, and according to [2,3], in order to get a successful BIM implementation is necessary the adjustment of projects development variables that need to be carefully studied for a better project performance. In Brazil, the BIM technology have been implemented in some privates and public enterprises like Brazilian Army and Foundation for the Education Development of Sao Paulo State - FDE, in search of better project development routines.

The goal of this paper is to analyses the BIM tools potential in Brazilian scenery, stablishing a comparison between the performance between CAD and BIM tools. The strategy to develop this paper was based on a technical review focused on periodical papers as well as a survey applied of experts of project development in Brazil. This paper is organized into sections as follows: introduction, technical review, case study, discussion, and finally, conclusions and references.

\section{2 - Technical review}

\subsection{Project development in Brazil}

Project process has been suffering, in Brazil, a big conceptual evolution, that amplify their function in the process. Nowadays projects are very important because they are a font for building process improvement. The importance of project elaboration is growing because it is the major source of improvement of building performance, reducing production costs and occurrence of faults in both product and process, generating an optimization in the implementation activities.

In this stage, the decision-making affects the costs, speed of execution and quality of project. If the right decisions are not taken at this stage, many problems can arise and be solved by different professionals, who are not necessarily qualified, contributing to higher costs and losses $[1,4]$.

Advances in project development were motivated by various market environmental factors in challenge of greater excellence in costs that could make companies more attractive to customers, who are becoming more rigorous. It can be seen, at Fig. 1, the importance of early stages (viability, conception and project development) for project development. Despite the low initial investment of resources, there is great potential for improving process, reducing the failures and enabling cost reduction. 


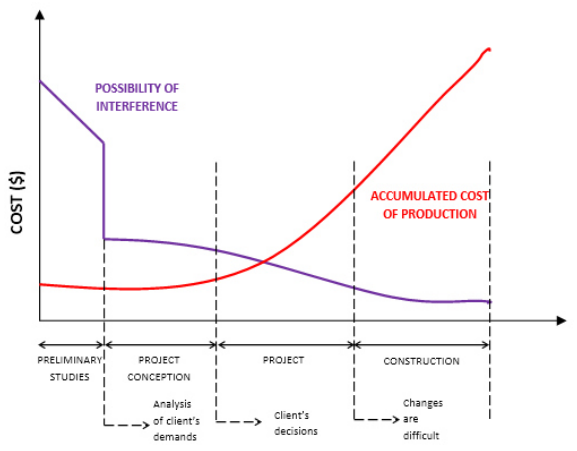

Fig. 1. Investment in Projects Adapted from [4]

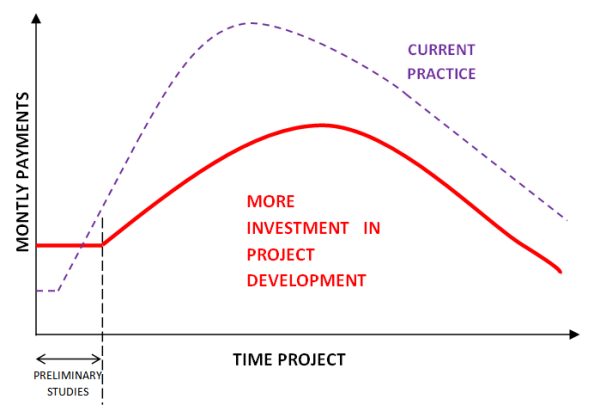

Fig 2. Costs and Monthly Payments Adapted from [4]

According [1], some entrepreneurs in Brazil understand projects like a cost in productive scenery. Great part of the enterprises starts raising money before construction (residential buildings). At this logic, the projects development has been seen like an expense, and the production team solves the problems of construction, that should be resolved before execution, in other words, at construction. A major investment at project development (fig. 2) allows costs reduction and redistribute de the payments during construction. It is possible because of the mayor variables control and project compatibility.

\subsection{CAD Tools}

The first applications of computers to assist the engineering steps began in the 1950s, when the Massachusetts Institute of Technology (MIT) started the discussion of CAD technology. CAD systems of this generation were limited to the description of twodimensional geometric entities, creating and manipulating drawings in monochrome graphics terminals. According [5], these systems has already propitiated advantages such as possibility of sending and receiving drawings by electronic means; management of drawings and information; precision in the design; faster recovery and modification or updating drawings.

During the years 1960-1980, the use of CAD systems has limited the application in large companies such as aerospace and automotive, because of the high costs involved, since software / hardware until qualification of the workforce, which required users with a greater degree of statement. However, at the end of the 90s, with the development of the Windows Operating System, a very robust for applications in PCs, there was a migration of companies that developed their UNIX systems for Windows. This fact has reduced the cost of hardware and the need for highly specialized users. In these first CAD tools, construction elements were the simple junction of geometric entities such as lines, arcs and curves. It was the direct transfer of drawing executed manually on the drawing board to the computer [5]. 
Besides all undeniable qualities of CAD implementation on project processes, for AEC - Architecture, Engineering and Construction - area, the CAD tools presented bottlenecks of integration quite difficult to be overcame. The vectorial software architecture became difficult $\mathrm{CAD}$ platform integration with other software, and this lack made the emergence of new software.

\subsection{BIM Tools}

BIM tools can be defined like CAD platforms improvements aiming AEC area. The BIM implementation is the utilization of information systems (IS) in the construction industry. It has been an issue of great importance in order to enhance the effectiveness of construction projects throughout their life cycle and across different construction business function, since construction until utilization [6].

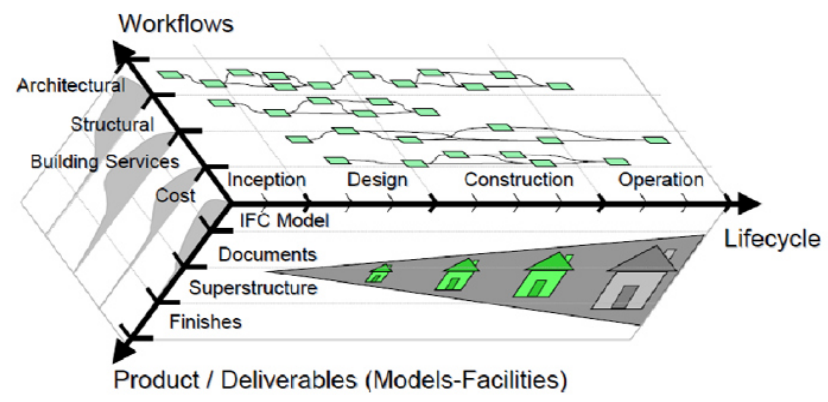

Fig. 3. - BIM Instances [7]

The main difference between BIM and CAD tools is the architecture of the software. The CAD software structure is vectorial while BIM tools are parametric. This characteristic permits the development of collaborative and tridimensional objects, where different professionals can work integrated. The BIM utilization on AEC area can integrate all the whole project process, since conception until construction and operation (fig. 3) [2].

These tools are used for visualizing and coordinating in the AEC (architecture, engineering and construction) area. By definition, permits avoiding errors and omissions, improves productivity, support scheduling, safety, cost and quality management. It incorporates all the building components, including geometry, spatial relationships, properties and quantities [8,9].

In general steps, the use of the tool improves an increase of efficiency and precision in project process, reduces the errors with a better information coordination, allows the simulation of some project components, generating of documentation to production, reduces the maintenance costs [9].

The enterprises are implementing BIM tools in their processes but this process are not equal worldwide. In the USA, for example, there is a great government effort for 
BIM implementation while in Brazil this implementation is happening in some companies alone. Therefore, to understand the BIM tools potential in front of CAD tools, there was made a case study to discuss about this subject.

\section{Case Study}

To understand the potential of BIM besides CAD tools in AEC enterprises of Sao Paulo region, in Brazil, there was made an online survey to experts, searching information about, last year:

-Type of projects developed;

-Total area projected;

-Number of professionals involved on project development;

-Total time spent on project development;

-Total time spent by each professional on project development;

-Team experience in software utilization.

This information could permit the establishment of metrics that could define the potential of the tools on project development in Brazilian scenery.

\section{1 - Sampling}

Ten companies of Sao Paulo Region were interviewed, formed by small, medium and large companies. There was $60 \%$ composed by small companies, $30 \%$ by medium and $10 \%$ large ones (fig. 4).

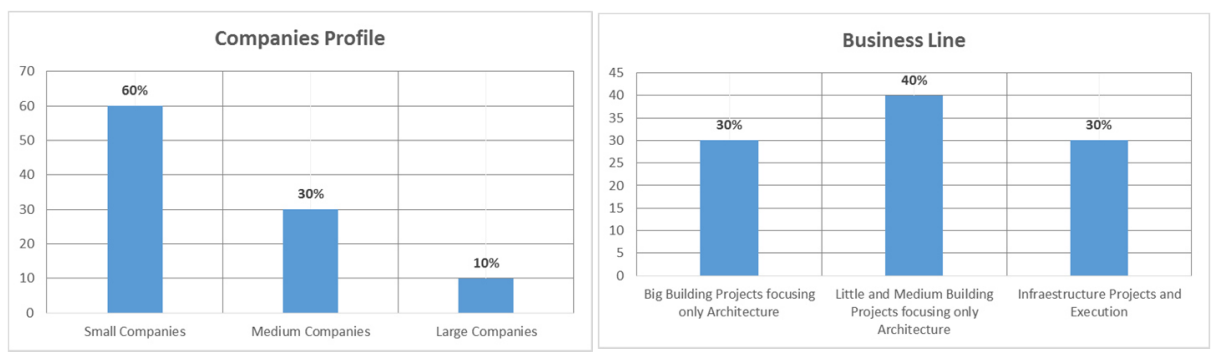

Fig. 4. Companies Profile

Fig 5. Business Line

The types of projects developed by the company are important to show how they are using of technology. To this survey, of respondents, $37,5 \%$ were big buildings projects focusing only architecture, $25 \%$ were little and medium building projects focusing only architecture, and $37 \%$ were infrastructure projects and execution (fig. 5). 


\section{2 - Software utilization and users profile}

From respondents, $44 \%$ of the companies uses BIM solutions while $67 \%$ of the respondents uses CAD solutions (fig. 6). The average experience of the companies using the tools are 10 years to BIM users and 12 years to CAD users (fig. 7).

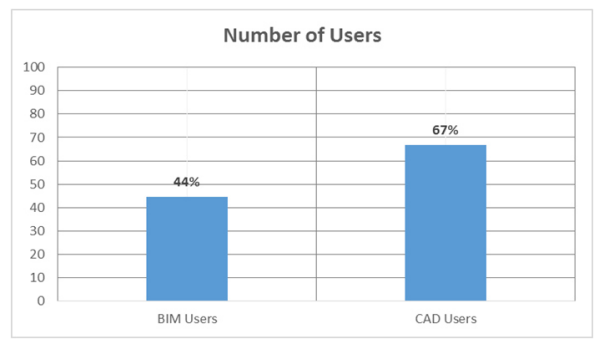

Fig. 6. Users type percent

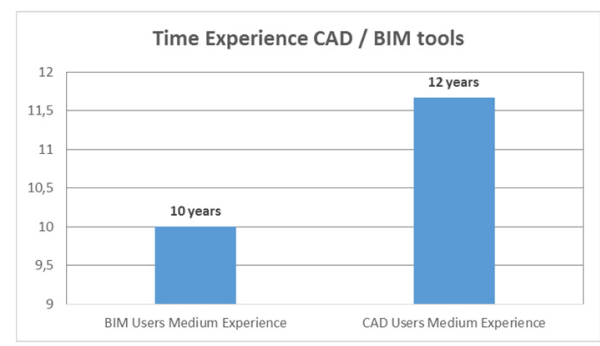

Fig 7. Time Experience

\section{3 - BIM x CAD productivity analysis}

Having a productivity parameter of the tools, there was made an analysis, in the last 12 months, about the quantity of projects developed by each company, analyzing: number of projects developed, square meters projected, professionals involved in the process and time expended by each designer. This information permitted the analysis of the time spent for square meter projected.

Besides these particularities, the tool utilization can change with particularities of project characteristics in construction area. There was made a comparison between the different project development steps in an enterprise. To initial steps, the designer spent less time and generates gross floor area compared with final projects (for execution) where the level of detailing is more effective. To compare these differences, there was compared the productivity between enterprises.

The results have shown that, to Basic Projects, the BIM users spent $0,44 \mathrm{~h}$ for square meter developed while CAD users spent $1,55 \mathrm{~h}$ for square meter. To Final Projects, BIM users spent $0,74 \mathrm{~h}$ for square meter while CAD users spent $1,08 \mathrm{~h}$ for square meter (figs 7,8).

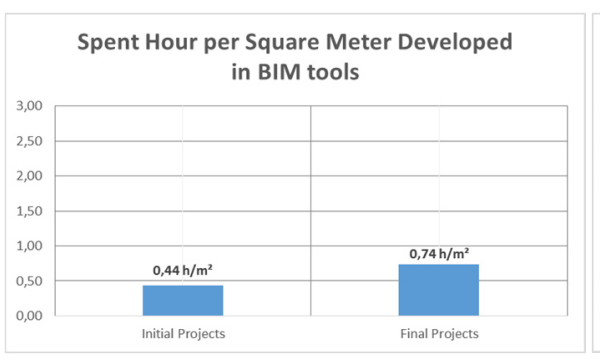

Fig. 7. BIM Users

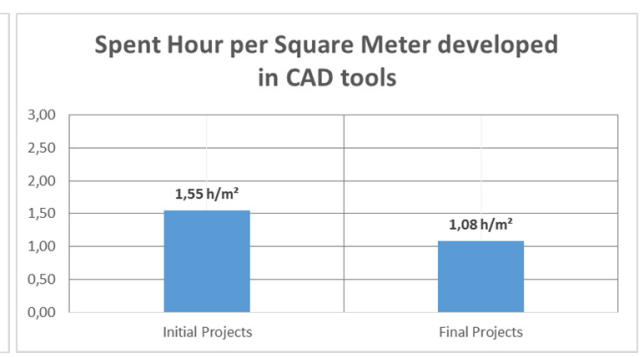

Fig 8. CAD Users 


\section{Discussion}

The BIM experts $[2,5,6,7,8,9]$ lists the qualities and effectiveness in tool utilization, besides they don't establish a difference of project development and its steps. The BIM tools, compared with CAD solutions, are more efficient, but, considering the project step, the differences are significant. The utilization of BIM tools to initial projects spent 0,44 hour for each square meter developed against 1,55 hour for each square meter in CAD tools. This fact denotes the efficiency of the tool in initial projects, where the time spent for each square meter is lower than other project steps.

To final projects, in both technologies, designers needed to spend more time in activities development, and the time grown up to 0,74 hour for each square meter developed by BIM users, and 1,08 hour for each square meter developed by CAD users. This consequence of different project instances definitions is not necessary at the initial projects. Even thought, BIM users spent less time than CAD users.

Another aspect to be considered, discussed by the authors cited, is the growing demand of informatics tools integration. BIM tools allows an integration of different project instances, what can permit, in the future, an optimization of the project time production in the final projects.

\section{Conclusions}

The informatics tools used in the civil construction scenario modified the project process development since their implementation. CAD tools became the project process more effective, but with difficult integration bottlenecks that was broken by BIM tools implementation.

The comparison of productivity between BIM and CAD shows that the first are more efficient than the conventional tools, considering different companies scenarios. Basic projects development using BIM tools spent $30 \%$ of the time used by CAD tools. It can be explained by the modeling facility interface. Otherwise, to final projects, BIM tools spents $68 \%$ of the time spent by CAD tools, what ratify the efficiency of them.

In the Brazilian scenery, the viability of BIM implementation can be guaranteed by the results obtained, demonstrating that even small offices can get good productivity returns with the implementation of the technology.

\section{Acknowledgment}

The authors would like to thank CAPES (Coordenação de aperfeiçoamento de pessoal de nível superior) and Paulista University (UNIP) for the financial support to develop this work. 


\section{$7 \quad$ References}

1. PERALTA, A.C. Um modelo do processo de projeto de edificações, baseado na engenharia simultânea, em empresas construtoras incorporadoras de pequeno porte. Master Dissertation in Production Engineering. Universidade Federal de Santa Catarina. (2002) Published Online https://repositorio.ufsc.br/bitstream/handle/123456789/.../188665.pdf (accessed on March 2015).

2. MIGILINSKAS, D.; POPOV, V.; JUOCEVICIUS, V; USTINOVICHIUS, L. The Benefits, Obstacles and Problems of Practical Bim Implementation in 11th International Conference on Modern Building Materials, Structures and Techniques, MBMST (2013). Science Verse. Published online http://dx.doi.org/10.1016/j.proeng.2013.04.097(acessed on: March 2015)

3. MEIRELES, A. R. Estratégia para uma integração avançada do BIM no processo construtivo in $3^{\circ}$ Seminário BIM - Sinduscon. Published Online (24/03/2013) http://www.sindusconsp.com.br/envios/2013/eventos/bim/Apresenta\%C3\%A7\%C3\%A3o_AntonioMeireles.pdf (accessed on March 2015).

4. FRANCO, L.S. Aplicação de diretrizes de racionalização construtiva para evolução tecnológica dos processos construtivos em alvenaria estrutural não armada. Tese de Doutorado em Engenharia Civil - Escola Politécnica da Universidade de São Paulo. São Paulo, 1992.

5. SOUZA, A.F.; COELHO, R.T. Tecnologia CAD/CAM - Definições e estado da arte visando auxiliar sua implantação em um ambiente fabril in XXIII Encontro Nacional de Engenharia de Produção - ENEGEP. Published Online (24/10/2003). www.abepro.org.br/biblioteca/ENEGEP2003_TR0504_0920.pdf (accessed on: March 2015).

6. JUNG, Y. ; JOO, M. ; Building information modelling (BIM) framework for practical implementation in Automation in Construction, n.20, p. 126-133. Published online http://10.1016/j.autcon.2010.09.010 (accessed on: March 2015)

7. MIGILINSKAS, D.; POPOV, V.; JUOCEVICIUS, V; USTINOVICHIUS, L., The Benefits, Obstacles and Problems of Practical Bim Implementation in 11th International Conference on Modern Building Materials, Structures and Techniques, MBMST (2013). Science Verse. Published online http://dx.doi.org/10.1016/j.proeng.2013.04.097(acessed on: March 2015)

8. CHEN, L.; LUO, H. A BIM-based construction quality management model and its application in Automation in Construction, n.46, p. $64-73$ (Oct 2014). Published online http:// doi:10.1016/j.autcon.2014.05.009 (accessed on: March 2015)

9. VOLK, R.; STENGEL, J.; SCHULTMANN, F. Building Information Modeling (BIM) for existing buildings - Literature review and future needs in Automation in Construction, n.38, p. 109-127 (March 2014). Published online http://doi:10.1016/j.autcon.2013.10.023 (accessed on: March 2015). 